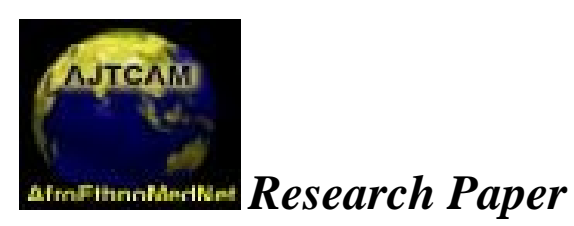

Afr. J. Infect. Diseases

www.africanethnomedicines.net

ISSN: 2006-0165@2009

\title{
ABSENCE OF mecA GENE IN METHICILLIN-RESISTANT STAPHYLOCOCCUS AUREUS ISOLATES
}

\author{
${ }^{1 *}$ B.O. Olayinka, ${ }^{2}$ A.T. Olayinka, ${ }^{1}$ A.F. Obajuluwa, ${ }^{1}$ J.A. Onaolapo and ${ }^{1}$ P.F. Olurinola \\ ${ }^{1}$ Department of Pharmaceutics \& Pharmaceutical Microbiology, Faculty of Pharmaceutical
}

Sciences,
Ahmadu Bello University, Zaria, Nigeria, ${ }^{2}$ Department of Medical Microbiology, Ahmadu Bello University Teaching Hospital, Shika-Zaria, Nigeria

*E-mail: busayoolayinka@yahoo.com ; +234 8037033156

\begin{abstract}
Methicillin-resistant Staphylococcus aureus has emerged as a serious threat to public health, causing both hospital and community-associated infections. The gold standard for MRSA detection is the amplification of the $m e c A$ gene that codes for the production of the altered penicillin-binding protein (PBP2a) responsible for classical methicillin resistance. This work determined the nature of methicillin-resistance observed in staphylococcal isolates. Staphylococcus aureus isolates with phenotypic resistance to methicillin (oxacillin) were tested for the carriage of the mecA gene by multiplex PCR to detect and type the SCCmec. The isolates were tested for the production of the altered PBP2a by latex agglutination test and $\beta$-lactamase production/hyper production by microplate Nitrocefin assay. None of the isolates hybridized with any of the 16 sets of primers representing the five major SCCmec types, nor contained the mecA gene; and none was positive for the gene product PBP2a determined by the MRSA screen latex agglutination test. Majority of the isolates $72.2 \%$ $(26 / 36)$ tested positive for $\beta$-lactamase production while $11 / 26(42.3 \%)$ were $\beta$-lactamase hyper producers. The MRSA phenotype observed in the isolates was not the classical mecA-mediated resistance, but most probably due to hyper-production of $\beta$-lactamase. Reports of loss of the mecA gene (believed to be stable) during storage and the fact that all PCR detection of mecA gene reported in Nigeria were done outside the country calls for attention on building local capacity for prospective molecular screening for MRSA in clinical and environmental isolates to adequately document their prevalence and monitor the increase. Appropriate guidelines should also be drawn up for the proper screening and reporting of MRSA isolates with the establishment of regional Reference Laboratories.
\end{abstract}

Key words: MRSA, mecA, Staphylococcus aureus, penicillin-binding protein, PBP2a.

\section{Introduction}

Staphylococcus aureus is a major pathogen both within hospitals and in the community (Stapleton and Taylor, 2002). In the pre-antibiotic era, the rate of mortality from invasive Staphylococcus aureus disease was high and the introduction of penicillin had a dramatic impact on treatment (Grubb, 1998). The semi-synthetic penicillin, methicillin was introduced in 1959 to overcome the problems that arose from the increasing prevalence of penicillinase-producing isolates of Staphylococcus aureus resistant to penicillin G and penicillin V. (Enright et al., 2002). Today, the whole world contends with methicillin-resistant Staphylococcus aureus (MRSA) as a major clinical problem (Benner, and Kaysser, 1968; Lowy, 1998) with many strains resistant to most other classes of antimicrobial agents (Panlilio et al., 1992; Speller et al., 1997). 
Strains of Staphylococcus aureus resistant to methicillin have been isolated as a frequent pathogen in hospital settings in patients with well-described risk factors (Lowy, 1998). The acronym MRSA is somewhat misleading because the semi-synthetic $\beta$-lactam, methicillin is no longer used to treat $S$. aureus infections; MRSA has come to traditionally represent $S$. aureus strains that are resistant to multiple antibiotics and associated with nosocomial infections. (Hiramatsu et al., 2001, Chambers, 1997, Foster, 2004).

The mechanism of methicillin resistance is the possession of an altered penicillin binding protein (PBP2a), that is encoded by the mecA gene carried on a mobile DNA element, the Staphylococcal cassette chromosome mec (SCCmec) (Lowy, 2003; Katayama et al., 2000). The mecA gene-product, PBP2a is an inducible, 76-78 $\mathrm{kDa}$ penicillin binding protein which in MRSA strains substitutes the other PBPs and because of its low affinity for all $\beta$-lactam antibiotics enables the organism to survive exposure to high concentrations of this class of antimicrobial agents (Chambers, 1997; Chambers, 2001; Lowy, 2003).

Detection of methicillin-resistance is complicated by the fact that mecA expression can either be heterogeneous or homogenous (Chambers, 1997). MRSA strains expressing heterogeneous resistance characterized by a predominantly low-level resistant population co-existing with a small proportion of highly resistant cells, are often misclassified as methicillin-susceptible Staphylococcus aureus (MSSA) by most conventional culture methods and thus represent a hidden reservoir in hospitals (Foster, 2004). It has been observed that the heterogeneous expression of methicillin resistance and the slow growth of the resistant bacteria can make detection difficult. Detection using methicillin and oxacillin is therefore aided by carrying out the test at neutral $\mathrm{pH}$; reduced incubation temperature of $33^{\circ} \mathrm{C}-35^{\circ} \mathrm{C}$; supplementing the agar/broth with $2 \%-4 \% \mathrm{NaCl}$ and $24 \mathrm{hr}$ incubation time.

\section{Methodology \\ Collection of isolates}

Suspected Staphylococcal isolates were collected from clinical specimens submitted to the diagnostic Medical Microbiology laboratory of the Ahmadu Bello University Teaching Hospital, Zaria over a cumulative period of 18 months.

\section{Identification of S. aureus isolates.}

Isolates were inoculated unto Mannitol Salt agar plates and incubated at $37^{\circ} \mathrm{C}$ for 24 to $48 \mathrm{hrs}$. Plates were examined for growth of colonies with the characteristic golden colouration. The isolates were characterized by their Gram stain characteristics, catalase test, slide and tube coagulase tests to confirm the $S$. aureus isolates (Baird, 1996).

\section{Determination of methicillin (oxacillin) susceptibility.}

Nutrient agar medium containing $5 \%$ of sodium chloride (Cookson and Phillips, 1990) was prepared, distributed in $20 \mathrm{ml}$ aliquots into bottles and sterilized at $121^{\circ} \mathrm{C}$ for 15 mins. Overnight cultures of the confirmed $S$. aureus isolates were emulsified in $3 \mathrm{ml}$ of Phosphate buffered solution (PBS) and turbidity adjusted to $0.5 \mathrm{McF}$ arland were inoculated unto the NA plates by swabbing. Oxacillin discs, $1 \mu \mathrm{g}$ (Oxoid, UK) were placed on the dried agar plates and incubated for $18 \mathrm{hrs}$ at $35^{\circ} \mathrm{C}$. The diameter of the zones of inhibition were measured and isolates classified as susceptible, intermediate and resistant based on CLIS interpretative chart of zone sizes (Cheesbrough, 2002; CLSI, 2006). Isolates with growth within the zone of growth inhibition were regarded as hetero-resistant strains.

\section{Molecular detection of methicillin-resistance gene}

A total of 36 isolates of Staphylococcus aureus with phenotypic resistance to methicillin/ (oxacillin1 $\mu \mathrm{g}$ ) and showing multiple antibiotic resistance (resistance to three antibiotic classes, apart from $\beta$-lactams) determined by DAD were selected for analysis and molecular detection of mecA gene. The isolates were part of those from specimens submitted to the diagnostic Medical Microbiology laboratory of Ahmadu Bello University Teaching Hospital, Shika-Zaria, Nigeria. 


\section{Multiplex PCR for detecting mecA gene and SCCmec type element assignment}

Chromosomal DNA was extracted from the isolates by a rapid boiling extraction method (Caddick et al., 2005). Staphylococcal Cassette Chromosome mec (SCCmec) element assignment was determined for all MRSA isolates using primers and cycle conditions previously described, Table 1 (Oliveira and de Lencastre, 2002). Multiplex PCR was performed using Gene Amp PCR system 9700 (Applied Biosystems, UK) in a $25 \mu \mathrm{l}$ reaction volume comprising of $17.7 \mu \mathrm{l} \mathrm{SDW}, 2.5 \mu \mathrm{l}$ of $10 \mathrm{x}$ primer mix (Table3.1) $0.2 \mu \mathrm{l}$ of $25 \mathrm{mM}$ dNTPs (Promega, UK), $0.1 \mu \mathrm{l}$ of 1.25 units/ $\mu \mathrm{l}$ Taq DNA polymerase (Promega, UK) and $2 \mu$ template DNA. SCCmec band pattern validation was carried out using the positive control strains COL, PER34, N315, ANS46, HU25 and MW2 representing SCCmec element types I, la, II, III, IIla and IV respectively. A $2 \%$ agarose gel containing $1 \mu \mathrm{g} / \mathrm{ml}$ of ethidium bromide was used to separate amplified fragments. Electrophoresis was performed in 1X TAE $(40 \mathrm{mM}$ Tris, $1 \mathrm{mM}$ EDTA and $0.1 \%(\mathrm{v} / \mathrm{v})$ glacial acetic acid) buffer at 100 volts for $1 \mathrm{hr}$.

Table1: Primers and stock concentrations used in SCCmec multiplex PCR (Oliveira and de Lencastre, 2002).

\begin{tabular}{|c|c|c|c|c|c|}
\hline Primer & Locus & Primer sequence $\left(5^{\prime}-3^{\prime}\right)$ & $\begin{array}{c}\text { 10x primer } \\
\operatorname{mix}(\mu \mathrm{M})\end{array}$ & $\begin{array}{l}\text { Amplicon } \\
\text { size (bp) }\end{array}$ & $\begin{array}{l}\text { Specificity } \\
\text { (SCCmec) }\end{array}$ \\
\hline A1 & A & TTCGAGTTGCTGATGAAGAAGG & 4 & 495 & I, la \\
\hline A2 & & ATTTACCACAAGGACTACCAGC & 4 & & \\
\hline B1 & B & АATCATCTGCCATTGGTGATGC & 2 & 284 & II \\
\hline B2 & & CGAATGAAGTGAAAGAAAGTGG & 2 & & \\
\hline C1 & C & ATCAAGACTTGCATTCAGGC & 4 & 209 & II, III, IIIa \\
\hline C2 & & GCGGTTTCAATTCACTTGTC & 4 & & \\
\hline D1 & D & CATCCTATGATAGCTTGGTC & 8 & 342 & I, II, IV, Ia \\
\hline D2 & & CTAAATCATAGCCATGACCG & 8 & & \\
\hline E1 & $\mathrm{E}$ & GTGATTGTTCGAGATATGTGG & 2 & 243 & III, IIla \\
\hline E2 & & CGCTTTATCTGTATCTATCGC & 2 & & \\
\hline F1 & $\mathrm{F}$ & TTCTTAAGTACACGCTGAATCG & 4 & 414 & III, IIIa \\
\hline F2 & & GTCACAGTAATTCCATCAATGC & 4 & & \\
\hline G1 & G & CAGGTCTCTTCAGATCTACG & 8 & 381 & II, la \\
\hline G2 & & GAGCCATAAACACCAATAGCC & 4 & & \\
\hline $\mathrm{H} 1$ & $\mathrm{H}$ & CAGGTCTCTTCAGATCTACG & 8 & 303 & III \\
\hline $\mathrm{H} 2$ & & GAAGAATGGGGAAAGCTTCAC & 4 & & \\
\hline MEC1 & $\operatorname{mec} A$ & TCCAGATTACAACTTCACCAGG & 8 & 162 & Internal \\
\hline MEC2 & & CCACTTCATATCTTGTAACG & 8 & & control \\
\hline
\end{tabular}

\section{Detection of PBP2a by MRSA Screen Latex agglutination test}

Detection of PBP2a was carried out using a slide agglutination kit (MRSA-Screen test Denka Seiken Co Ltd. Japan) and performed according to the manufacturer's instructions. EMRSA-15 was used as a mec-positive control strain and Oxford Staphylococcus aureus NCTC 8325 as a mecnegative control strain. The sample colonies were taken from a fresh $\mathrm{BHI}$ agar plate and re-

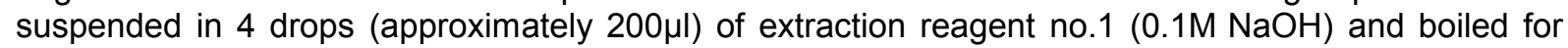
$3 \mathrm{~min}$. Following boiling 1 drop (approximately $50 \mu \mathrm{l})$ of extraction reagent no.2 $\left(0.5 \mathrm{M} \mathrm{KH_{2 }} \mathrm{PO}_{4}\right)$ was aliquoted into the suspension mix and vortexed for 30 seconds. The sample was then centrifuged at $1,500 \times \mathrm{g}$ for $5 \mathrm{~min}$ at room temperature. A $50 \mu \mathrm{l}$ sample of the test isolate supernatant, the positivecontrol and the negative-control was placed on the provided slides. One drop (approximately $25 \mu \mathrm{l}$ ) of anti-PBP2a monoclonal antibody-sensitized latex was added to each sample for the positive control and one drop (approximately $25 \mu \mathrm{l}$ ) of negative-control latex was added to each sample for a negative control. The slides were rotated by hand for 3 mins and characteristic agglutination indicated a positive result for PBP2a production.

\section{Determination of $\beta$-lactamase hyper production by Microplate Nitrocefin assay}

The $1 \mathrm{mg}$ lyophilized Nitrocefin powder (Oxoid, UK) was reconstituted in $1.9 \mathrm{ml}$ of $0.1 \mathrm{M}$ phosphate buffer, pH7 supplied by the manufacturer. The reconstituted Nitrocefin was further diluted 1 in 10 with PBS to give $50 \mu \mathrm{g} / \mathrm{ml}$ solution. The disrupted cell preparations were used immediately by dispensing $50 \mu \mathrm{L}$ of preparation into separate wells of a 96 well plate. $50 \mu \mathrm{L}$ of diluted Nitrocefin solution was added into each of the wells and incubated at $37^{\circ} \mathrm{C}$ for $10 \mathrm{mins}$. In the presence of $\beta$ - 
lactamase, the chromogenic nitrocefin substrate changes colour from yellow to pink/red. A positive control was set up with MRSA-15.

\section{Results}

The staphylococcal isolates from clinical and environmental samples were made up of 254 (75.8\%) Staphylococcus aureus, out of which a total of $139(54.7 \%)$ were resistant to methicillin as determined by DAD method on Nutrient agar medium containing $5 \%$ of sodium chloride. Twenty-seven isolates, representing $8.0 \%$ yielded hetero-resistant strains that were able to grow within the zone of growth inhibition. The distribution of the MRSA isolates by source is shown in Figure 1 . Most of the isolates were from wound $(42 \%)$, urine $(15 \%)$ and urethral swab $(11 \%)$.

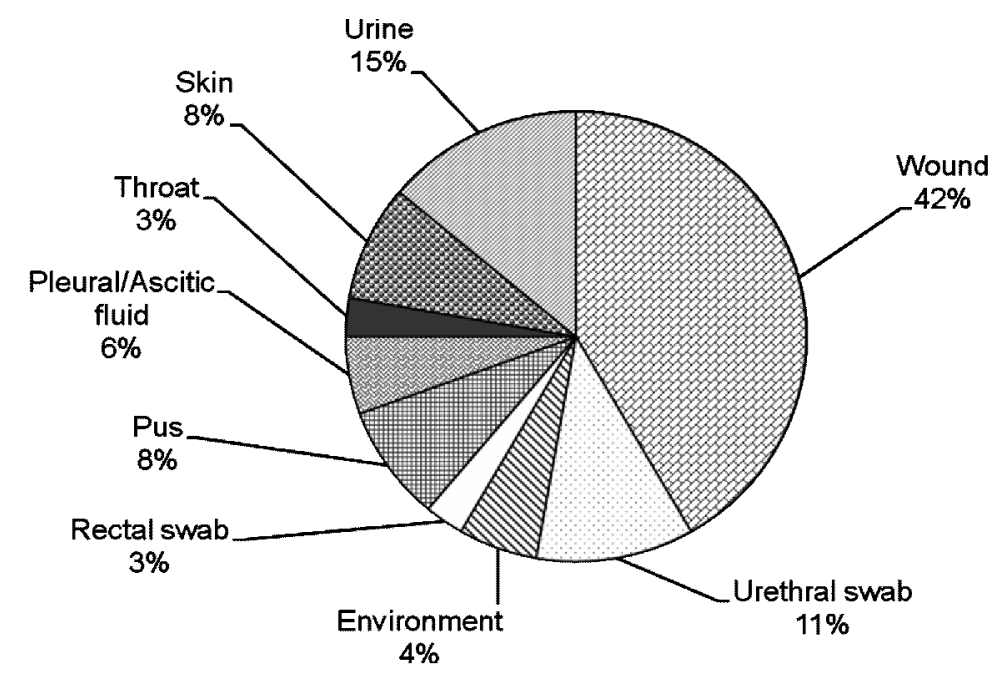

Figure1: Distribution of MRSA isolates by source.

\section{Multiplex PCR for detecting mecA gene and SCCmec type element assignment}

All the isolates were mecA-negative since there was no amplification of target DNA primers in the PCR run (Plate 1).

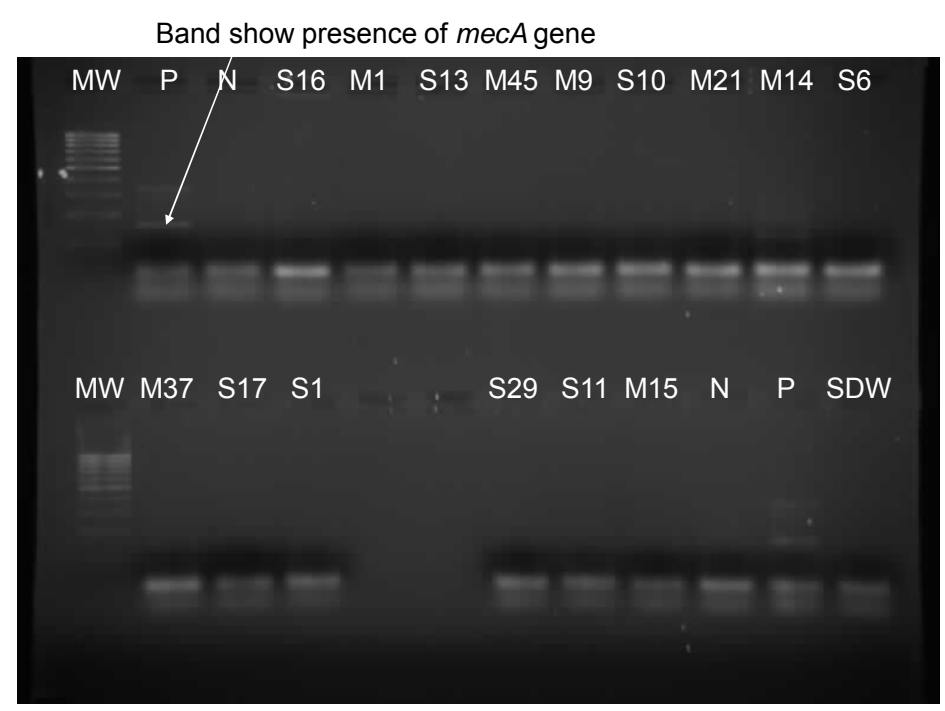

Plate 1: Multiplex PCR on isolates for $S C C m e c$ type assignment. $P=P o s i t i v e$ control, $N=N e g a t i v e$ control, MW=Molecular weight marker, SDW=Sterile distilled water. 


\section{Detection of PBP2a by MRSA Screen Latex agglutination test}

The presence of the mecA gene product PBP2a was determined in isolates by the MRSA Screen Latex agglutination test kit (Denka Seiken Co Ltd. Japan).

None of the isolates were PBP2a-positive, since there was no characteristic agglutination except in the positive control, EMRSA-15 (Plate 2).

\section{Detection of $\beta$-lactamase hyper-production.}

Hyper-production of $\beta$-lactamase in isolates was detected by the intensity of the colour change in the Microplate Nitrocefin assay compared with the positive control (MRSA-15). A total of 26 out of the $36(72.2 \%)$ isolates tested produced $\beta$-lactamase giving the positive colour change from yellow to pink within the 10 mins of incubation time. Intense colour change greater than control was observed in $11 / 36(30.6 \%)$ of isolates.

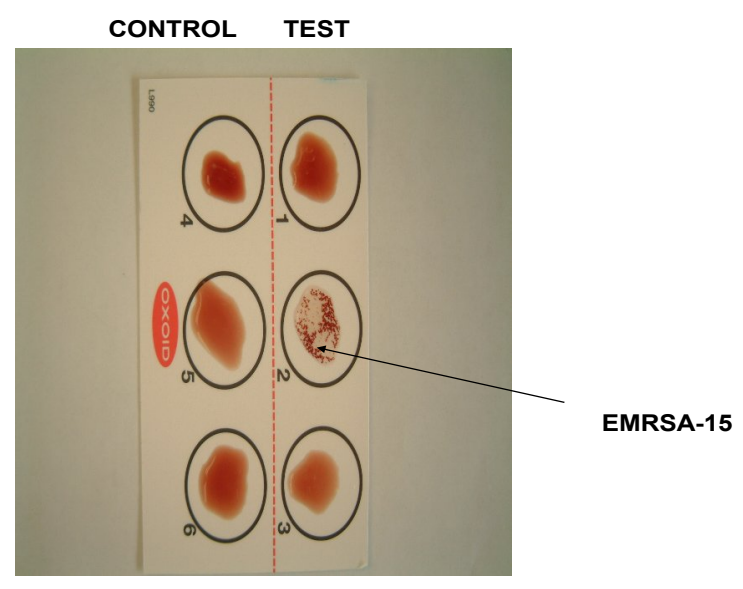

Plate 2: MRSA Screen Latex agglutination test result shows agglutination in the mecA-positive control (MRSA-15).

\section{Discussion}

The distribution of MRSA by source in this study is consistent with various studies that identified wounds (surgical/burns), urine and pus/abscess as important sources of MRSA isolation (Daxboeck et al., 2004; Orrett and Land, 2006).

Determination of methicillin (oxacillin) susceptibility of isolates by the DAD method revealed a worrisome $54.7 \%$ resistance rate. The rate of MRSA in this study is higher than those reported by other investigators in the country. In a survey on the prevalence of MRSA in eight African countries and Malta, Kesah et al. (2003) reported the highest rate of $29.6 \%$ for Lagos University Teaching Hospital, Nigeria. Taiwo et al. (2004) reported a rate of $34.7 \%$ for Ilorin; Olonitola et al (2007) reported a rate of $33.3 \%$ from a Federal Medical Centre and Ikeh (2003) had a rate of $43 \%$ for Jos.

Onanuga et al. (2006) reported a higher rate of $71.1 \%$ from urine of healthy women while Ikeh and Yakeu (2006) reported an alarming 92.6\% MRSA out of the $S$. aureus isolated from bacteria flora on the hands of nursing service workers.

A common factor in all these studies is the method of detecting MRSA; the DAD susceptibility test against $5 \mu \mathrm{g}$ methicillin or $1 \mu \mathrm{g}$ oxacillin, which is generally regarded as less specific in detecting classical methicillin resistance mediated by $\operatorname{mec} A$ gene that codes for the production of an additional penicillin binding protein, PBP2a or PBP2' which confers resistance to all $\beta$-lactam antibiotics (Brown et al., 2005).

Methicillin resistance isolates with alterations to the existing PBPs have been described (Chambers et al, 1989; Montanari et al., 1990; de Lencastre et al., 1991) and they are termed moderately resistant $S$. aureus (MODSA). Under some test conditions it has also been reported that isolates which produce large amounts of penicilinase ( $\beta$-lacatmase hyper producers) show low level 
resistance to oxacillin and have been referred to as Borderline oxacillin-resistant S. aureus (BORSA) (Chambers et al., 1989). The clinical importance of MODSA and BORSA strains had been doubtful, since there had been no treatment failures with penicillinase resistant penicillins (Thauvin-Eliopoulos et al., 1990; Hirano and Bayer, 1991).

Although the disc diffusion method remains the most widely used in routine clinical laboratories, it has been suggested that oxacillin (methicillin) be replaced by cefoxitin, a more potent inducer of mecA expression, that is less affected by test conditions and hyperproduction of penicillinase (Brown et al., 2005). With the cefoxitin disc becoming increasingly available, it is hoped that this will eventually replace oxacillin (methicillin) in clinical laboratories and research work on MRSA prevalence.

The gold standard for detection of MRSA is the polymerase chain reaction, $\mathrm{PCR}$ that detects the mecA gene (Berger Bächi and Roher, 2002) or alternatively detecting the mecA gene product PBP2a by latex agglutination tests.

All the 36 isolates selected for molecular characterization by the amplification of the genetic determinant of methicillin resistance, mecA gene by the multiplex-PCR typing of the SCCmec element that carries the gene revealed that none of the isolates carried the mecA gene.

Most reports of MRSA in Nigeria have been based on the DAD test results (Taiwo et al., 2004; Ikeh, 2003; Onanuga et al., 2006; Ikeh and Yakeu, 2006). The reports of molecular detection of MRSA have been limited and had different rates for MRSA detected by DAD test and amplification of the mecA gene.

Adesida et al. (2005) reported that of the $276 \mathrm{~S}$. aureus isolates tested, $26 / 276(9.4 \%)$ seemed to be MRSA based on zone of inhibition diameter but only $4 / 26(1.4 \%)$ carried the mecA gene and contained the mecA gene product, PBP2a determined by MRSA-Screen latex agglutination test. Shittu et al. (2006) found $3 \%$ of isolates resistant to oxacillin but only $3 / 200(1.5 \%)$ were confirmed to be MRSA by PCR detection of the mecA gene. None of the isolates in this study produced the altered PBP2a. The question is what then is the nature of the methicillin resistance observed in these and other isolates in this study? Various other mechanisms have been adduced for observed methicillin resistance in S. aureus (Chambers, 1997; Brown et al., 2005). Strains of $S$. aureus with reduced susceptibility to penicillinase-resistant-penicillins (PRP) have been categorized as follows;

- 'Classical' MRSA which produce the altered, low-affinity PBP2a, encoded by the mecA gene

- The borderline (low-level)-methicillin resistant strains of $S$. aureus (BORSA) generally considered as being due to hyper-production of type-A- $\beta$-lactamase. These BORSA strains are mecA-negative, PBP2a-negative

- Strains with modified 'normal' PBPs due to altered binding capacity or over-production of PBPs. These strains are termed MODSA.

A total of $26 / 36(72 \%)$ of isolates tested by the microplate Nitrocefin assay produced $\beta$-lactamase while $11 / 36(30.6 \%)$ hyper-produced $\beta$-lactamase. The methicillin-resistance observed in the mecAnegative, PBP2a-negative $S$. aureus strains in this study may therefore be attributable to the hyperproduction of $\beta$-lactamase in only $30.6 \%$ of the isolates tested. This can definitely not explain the high rate of phenotypic MRSA detected in this study.

The SCCmec element containing the mecA gene was generally believed to be stable after incorporation into the strain. However, Griethysen et al. (2005) reported the loss of the mecA gene during storage of $36 / 250(14.4 \%)$ confirmed MRSA strains at $-80^{\circ} \mathrm{C}$ with the MicroBank system (ProLab Diagnostics, Canada). The molecular characterization of isolates in this study as well as the two known reports (Adesida et al., 2005; Shittu et al., 2006) were all carried out abroad which would have meant collecting the isolates over a period of time, preliminary characterization, storing and subculturing over a considerable length of time before final transportation for molecular characterization. It is therefore not impossible given our power situation that some classical mecA-containing isolates might have lost the gene on prolonged storage at temperature much higher than $-80^{\circ} \mathrm{C}$.

\section{Conclusion}

The phenotypic methicillin-resistance observed in staphylococcal isolates by the DAD test was not due to the production of the altered PBP2a encoded by the mecA-gene. The $\beta$-lactamase hyperproduction observed in some of the isolates might have been responsible for their 'masquerading' as MRSA. However, the multiply resistance nature of these MSSA strains and the ability of Staphylococcus aureus to take up the mecA-gene, calls for continual surveillance for MRSA and the drawing up of guidelines for the prompt, effective and reliable detection of MRSA in resource limited setting like ours. MRSA has emerged as an important nosocomial and community-associated pathogen with constantly changing epidemiology worldwide. There is nothing more international as 
infection and there are no barriers to a multidrug resistant pathogen carried across borders by man. Though classical mecA-mediated MRSA seems not to be a problem yet in our hospitals, now is the time to build local capacity in understanding and dealing with this clinically important pathogen with worldwide public health importance.

\section{Acknowledgement}

The authors are grateful to Mr. Ega Bawa of the Dept of Medical Microbiology, ABUTH, ShikaZaria, Nigeria; Prof. P.A. Lambert and Dr. Jessica Rollason of School of Life \& Health Sciences, Aston University, Birmingham, UK for their help on detection of mecA gene in the isolates. We thank the Carnegie Foundations (Projects for Capacity Building) for providing the resources that allowed BOO work at Prof. Peter Lambert's laboratory as a Visiting Researcher.

\section{References}

1. Adesida S, Boelens H, Babajide B, Kehinde A, Snijders S, van Leeuwen W, Coker A, Verbrugh $\mathrm{H}$ and van Belkum A (2005) Microbial Drug Resistance 11(2): 115-121.

2. Baird D(1996) Staphylococcus: cluster forming cocci. In: Collee JG, Fraser AG, Marimion BP and Simmons A (eds) Practical Medical Microbiology, 14th Ed. Edinburgh. Churchill Livingstone, Ltd. 245-261.

3. Benner E J and F H Kayser (1968) Growing clinical significance of methicillin-resistant Staphylococcus aureus Lancet ii: 741-744.

4. Berger-Bächi B, Rohrer S. (2002) Factors influencing methicillin-resistance in staphylococci. Arch. Microbiol. 178: 165-171.

5. Brown D.F.J, D.I. Edwards, P.H. Hawkey, D.Morrison, G.L Ridgway, K.J. Towner and M.W.D Wren, on behalf of the Joint Working Party of British Society for Antimicrobial Chemotherapy, Hospital Infection Society and Infection Control Nurses Associated (2005). Guidelines for the laboratory diagnosis and susceptibility testing of methicillin-resistant Staphylococcus aureus (MRSA) J. Antimicrob Chemother. 56: 1000-1018.

6. Caddick, J. M., Hilton, A. C., Rollason, J., Lambert, P. A., Worthington, T. and Elliott, T. S. (2005) Molecular analysis of methicillin-resistant Staphylococcus aureus reveals an absence of plasmid DNA in multidrug-resistant isolates. FEMS Immunol Med Microbiol 44, 297-302.

7. Chambers H.F. (1997) Methicillin resistance in Staphylococci: molecular and biochemical basis and clinical implications. Clin. Microbiol. Rev. 10: 781-791.

8. Chambers HF, Archer G, Matsuhashi M. (1989) Low-level methicillin-resistance in strains of Staphylococcus aureus. Antimicrob. Agents Chemother. 33: 424-8.

9. Chambers, H.F (2001). The Changing epidemiology of Staphylococcus aureus? Emerging Infections Diseases 7: 178-182.

10.Cheesbrough M. (2002) District Laboratory Practice in Tropical Countries. Part 2. Cambridge University Press. UK. pp.136-142.

11. Clinical Laboratory Standards Institute (2006) Performance Standards for Antimicrobial Susceptibility Testing; Sixteenth Informational Supplement. CLSI Document M100-S16. Wayne, PA 19087-1898, USA. Pg.46

12.Cookson B. and Phillips, I. (1990) Methicillin - Resistant Staphylococci. J. Appl Bacteriol. Symposium Supply. Series No. 19, 69: 55270 S.

13.Daxboeck F, Assadian O, Apfalter P and Koller W (2004) Resistance rates of Staphylococcus aureus in relation to patient status and type of specimen. Journal of Antimicrobial Chemotherapy 54; 163-167.

14.de Lencastre H, Sa Figueiredo AM, Urban C et al (1991) Multiple mechanism of methicillinresistance and improved methods for detection in clinical isolates of $S$. aureus. Antimicrob Agents Chemother. 35: 632-9.

15.Enright M.C. Robinson D.A., Randle G. Feil E.J., Grundnann H., Spratt B.G. (2002). The Evolutionary history of methicillin-resistant. Staphylococcus aureus (MRSA). Proc. Natl. Acad Sci. U.S.A. 99: 7687-92.

16.Foster T.J (2004) The Staphylococcus aureus "superbug". J. Clinical Investigation, 114: 16931696. doi: $10.1172 / \mathrm{JCl} 200423825$.

17.Grubb, WB (1998) Genetics of MRSA. Rev. Med. Microbiol 9: 153-162.

18. Hiramatsu, K., Ciu. L, Kuroda M and Ito T. (2001). The Emergence and evolution of methicillin resistant Staphylococcus aureus. Trends Microbiol. 9: 486-493. 
19. Hirano L and Bayer AS (1991) Beta-lactamase- Beta-lactamase-inhibitor combinations are active in experimental endocarditis caused by beta-lactamase-producing oxacillin-resistant staphylococci. Antimicrob. Agents Chemother. 35:685-690.

20.Ikeh El (2003) A twelve-month surveillance of MRSA at Jos University Teaching Hospital. Afr. J Clin Exper. Microbiol. 4(1): 52-55.

21. Ikeh El and Yakeu G(2006) Microbial handflora of nursing services workers in a Nigerian University Teaching Hospital. Nigerian Medical Practitioner 50(1): 12-14.

22. Katayama Y, T. Ito and K. Hiramatsu (2000) A new class of genetic element Staphylococcus cassette chromosome mec encodes methicillin resistance in $S$. aureus. Antimicrob. Agents Chemother. 44: 1549-1555.

23.Kesah C., S. BenRedjeb, T.O. Odugbemi, C.S.B. Boye, M. Dosso, J.O. Ndinya Achola,, S. Koulla-Shiro, M. Benbachir, K. Rahal and M.Borg (2003) Prevalence of methicillin-resistant Staphylococcus aureus in eight African hospitals and Malta. Clin. Microbiol Infect; 9: 153-156.

24.Lowy F.D. (2003) Antimicrobial Resistance: the example of Staphylococcus aureus. Journal of Clinical Investigation III (9): 1265-1273.

25.Lowy, FD (1998) Staphylococcus aureus infections N. Engl. J. Med. 339: 520-532.

26. Montanari MP, Tonin E, Biavasco F et al. (1990) Further characterization of borderline methicillin-resistant Staphylococcus aureus and analysis of penicillin-binding proteins. Antimicrob. Agents Chemother 34: 911-13.

27. Olivera DC and de Lencastre H. (2002) PCR strategy for rapid identification of structural types and variants of the $m e c$ element in methicillin-resistant Staphylococcus aureus. Antimicrob. Agents Chemother 46 : 2155-61.

28. Olonitola OS, Olayinka BO, Sani FD (2007) Antibiotic susceptibility of Staphylococcus aureus isolates from a Nigerian Federal Medical Centre. Cameroon Journal of Experimental Biology 3(2):97-102.

29. Onanuga A, Olayinka BO, Oyi AR, Onaolapo JA (2006) Prevalence of community-associated methicillin-resistant Staphylococcus aureus (MRSA) isolates among women in Federal Capital Territory (Abuja), Nigeria. J. College of Medicine 11(1): 47-52.

30. Orrett F A and Land M (2006) Methicillin-resistant Staphylococcus aureus prevalence: Current susceptibility pattern in Trinidad. BMC Infectious Diseases 6:83 (http://www.biomedcentral.com/1471-2334/6/83 )

31.Panlilio, AL, Culver DH, Gaynes RP, Bannerjee, S, Henderson T.S, Tolson JS and Martone W. J (1992) Methicillin-resistant Staphylococcus aureus in US hospitals. Infect control Hospital Epidemiol 13:582-586.

32.Shittu A, Lin J and Kolawole D (2006) Antimicrobial Susceptibility Patterns of Staphylococcus aureus and Characterization of MRSA in Southwestern Nigeria. Wounds 18: 77-84.

33.Speller, DC, Johnson AP, James D, Marples R.R, Charlett A and George R.C (1997). Resistance to methicillin and other antibiotics in isolates of Staphylococcus aureus from blood and cerebrospinal fluid, England and Wales, 1989-1995. Lancet 250: 323-325.

34.Stapleton P.D and Taylor P.W (2002) Methicillin resistance in Staphylococcus aureus: mechanisms and modulation. Science Progress 85(1): 57 -72.

35. Taiwo SS, Onile BA, Akanbi II AA (2004) Methicillin-resistant Staphylococcus aureus (MRSA) isolates in Ilorin, Nigeria. Afr. J. Clin Exper. Microbiol. 5(2): 189-197.

36. Thauvin-Eliopoulos, C., L.B. Rice, G.M. Eliopoulos and R.C. Moellering (1990). Efficacy of oxacillin and ampicillin-sulbactam combination in experimental endocarditis by a $\beta$-lactamasehyper producing Staphylococcus aureus. Antimicrob. Agents Chemother. 34: 728-732.

37.van Griethuysen A., van Loo I., van Belkum A., Vandenbroucke-Grauls C., Wannet W., van Keulen P. and Kluytmans J. (2005) Loss of the mecA gene during storage of methicillin-resistant Staphylococcus aureus (MRSA) strains. J. Clin. Microbiol. 43: 1361-65. 